\title{
Health Workers Attitude/Behavioural Influence on Women Access to Primary Health Care Services in Orumba North lga, Anambra State, Nigeria.
}

\author{
Igwe, Ijeoma \\ Lecturer, Sociology and Anthropology Department. University of Nigeria \\ Ojua, T. Asu \\ Senior Lecturer, Sociology Department. University of Calabar. Nigeria. \\ taojua2007@yahoo.com \\ Atama, Chiemezie \\ Lecturer, Sociology and Anthropology Department. University of Nigeria \\ Ugwu, Chidi \\ Lecturer, Sociology and Anthropology Department. University of Nigeria
}

Obekezie, D. S.

Professor of Sociology and Anthropology Department. University of Nigeria

\begin{abstract}
Lack of access to Primary Health Care (PHC) services has consistently posed serious health risks in Nigeria, especially in rural areas where health facilities are largely inadequate or absent in extreme cases. Cross-sectional survey research design was used to generate data for the study. Both quantitative and qualitative research approaches were used to investigate women who are responsible for caring their children to these PHC services. A total Six hundred women aged between 15-49 years formed the study sample and 600 questionnaires were administered by the researchers. Eight Focus Group Discussions (FGDs) with community members and in-depth interviews (IDI) with health workers were held. Results from multiple regression analysis with a $<0.001$ level of significance showed that the situation of PHCs in the study area was seriously poor and personnel problems which revolved around the attitude of health workers, and includes long waiting/appointment time given to patients or clients were the major challenges the people encountered in accessing PHC services in the LGA and these were supported by the qualitative data. The FGD data showed that mothers were often reluctant to visit the health facilities because of the shabby manner in which the health workers related and treated them. The study therefore recommends more Government presence in the rural areas in the form of provision of facility, medical consumables, employment of trained health workers and adequate sensitization and improved rural participation and capacity building workshops for workers on health issues.
\end{abstract}

KEY WORDS: Access, Attitude, health workers, Primary Health Care Services. 


\section{INTRODUCTION}

High rate of death among children under-five years remains one of the most salient global health concerns in contemporary society. More than 10 million children below five years of age die every year around the world. In developing countries for example, child health and survival lag behind desired targets, due to infant and child mortality. About 29,000 children under the age of five die each year mainly from preventable health, behavioral and socioeconomic causes or challenges especially amongst rural dwellers (UNICEF, 2008). According to WHO (2011), an estimated four million children die each year during the first 28 days of life, a large proportion of which occur during the first 24 hours and this is attributed to lack of adequate facilities and availability of health workers who are willing to discharge their duties and at the right time. The situation is particularly worrisome in sub-Saharan Africa where infant and child mortality rates are 10 times higher than the industrialized regions (Barbieri, 2004). The 2008 Nigerian Demographic and Health Survey (NDHS) put under five mortality rate in Nigeria at 157/1000 and this collaborated with the findings of NPC \& ICF Macro, (2009). This is disturbing when it is compared with the target of 45/1000 set to be achieved in 2015, as a global standard.

Access to health care services is commonly defined as one's ability to obtain and appropriately use good quality health technologies and commodities as and when needed for good health (Ensor \& Cooper, 2004), effective access to health care services by women and children remains limited and problematic in Nigeria. For instance, the 2008 Nigerian Demographic and Health Survey (NDHS) revealed that only $23 \%$ of children aged 12-23 months, the age by which they should have received all vaccinations, were fully vaccinated. Fifty percent received vaccinations for BCG and 41\% for measles. Fewer children received DPT 3 (35\%) and polio 3 (39\%), compared with those who received DPT 1 (52\%) and polio 1 (68\%). Only $19 \%$ of children are fully immunized by 12 months of age. Overall, $29 \%$ of children in Nigeria have not received any vaccinations.

According to Frost and Reich (2008) the prevailing maternal and child mortality rate in developing countries is because many people do not have access to health care services especially the rural dwellers, principally due to their detaste and feelings of ill treatment by the health care providers, hence their desires to patronize alternative services including traditional outlets (Ojua, Ishor \& Ndom, 2013). The low child health status and poor uptake of interventions designed to promote child health in Nigeria are largely attributable to poor antenatal care (ANC) practices, lack of access to and weak health systems. The situation is further aggravated by poverty, ignorance and attitude of health workers which account for women's inability to access critical ANC services and counseling on important safety measures, drugs and other interventions like ITN use (Onokerhoraye, 2000). In many cases, medical facilities are few and thinly spread. In the hard to reach rural areas, with difficult terrain and poor road network, modern health facilities are luxuries because the dwellers can hardly afford, even when they wish (Okonofua, 2010). Attendance at ante natal clinics (ANC) is very poor for a number of personal and logistic issues confronting mothers especially with respect to distance, means of transport and most times attitude of health staff. This position is however supported by the study carried out by Onyeneho (2005) who argued that failure to access child health programmes in developing countries depends upon bridging gaps in delivery and community utilization of services.

The foregoing problems and issues tend to suggest that increased maternal and child mortality in the country is related to poor access to Primary Health care services. While the problem may be the same in most Nigerian communities, the actual manifestation and explanatory factors may differ from one locality to another even among social groups within the same society. This 
agrees with the view of Frost and Reich (2008:xi) when they concluded that "just because a good health technology exists, does not mean that it will be delivered, used or achieve its potential to bring good health". It is therefore, the major challenge of this study, to identify how attitude of health workers affect access to primary health care services in rural Anambra State, Nigeria.

\section{STUDY DESIGN}

This study adopted the cross-sectional survey research design. It was developed to help determine and generate data on the attitude and behavior of health workers and access to PHC services in rural Orumber North of Anambra State of Nigeria.

\section{Study Area}

The study was carried out in Orumba North Local Government Area of Anambra State, Nigeria. The choice of Orumba North LGA, a typical rural area for this study is because of the different problems associated with access to PHC services in the area. They are predominantly farmers at subsistent levels and petty traders with very few engaged in civil service jobs. Being a typically rural populace, they are very tied to their different cultural practices and very religious. Most dominant are the traditional religious worshipers and newly introduced Christian religious adherents. The major source of income for the people in this area is agriculture and as a result, they produce different food crops. Apart from farming, the people in this area are also traders and very few of them engage in white collar jobs. However, the residents are very poor as this affects negatively their state of health and their children are at the receiving end.

\section{Study Population}

The NPC (2006) population census showed Orumba North LGA with a population of 172, 405 with a land mass of about 32.4 Square Kilometers. The target population for this study was all mothers of child bearing age (15-49years) in the L.G.A. This constituted $22 \%$ of the total population (NPC.2006). This target population in 2011 is estimated at 43,545. The focus on this segment of the population is justified with the fact that women and children are the major users of the PHC services. They have also experienced the problems of access to health care services (Rashid et al. 2001) According to (NPC and ICF Macro, 2009), only 51.9\% of the Children have received all basic immunizations in Anambra State. This figure represented the rate of access to PHC services and thus was used as the preparation or rate of occurrence with 95\% confidence level and 4.0 accuracy level,, a sample size of 599 respondents was computed. This was rounded up to 600 for proper distribution in the area of study.

\section{METHODOLOGY}

A multistage cluster sampling procedure, which entails successive selection of community clusters, Villages, housing units and respondents was employed. First the Communities were grouped into two clusters A and B with each of the clusters consisting of 8 communities.

Two Communities were randomly selected from each cluster making it four communities. From each of the four communities chosen, 3 Villages were randomly selected from them making 12 Villages in all. In each chosen Village, all the dwelling units were numbered, and of which a sample of 50 dwelling units were selected using systematic exampling technique. In each selected dwelling unit one eligible respondent was selected purposively, taking into account her age and the number of children she has. The study used questionnaire as quantitative instrument as well as Focus Group Discussion to collect data from respondents. 
A uniform set of questionnaire was administered to all 600 respondents selected randomly. The questionnaire sought information on socio-demographic characteristics of the respondent's, attitude and behaviors of health workers and other barriers to accessing PHC services in the L.G.A. Qualitative data were obtained through the use of FGDs. This provided indepth knowledge on how the attitude of heath workers affected access to the utilization of PHC services in this locality._A total of 8 FGDs were conducted with each group consisting of 8-10 persons. In each community 2 sessions of FGDs were held with one male group and one female group of the respondents who have children.

\section{DATA ANALYSIS}

For the qualitative data, the Atlas-Ti was employed in generating illustrative quotes from the information gathered. The quantitative data were first edited for comprehensiveness, completeness, uniformity and then coded before entering it into Epi-info software and later transferred to SPSS computer software for the actual analysis. Simple descriptive statistics such as percentages mean and graphical illustration were employed in presenting the main characteristics of the study subject. Multiple regression analysis was also done to illustrate the relationship between selected important variables and access to health care services.

\section{RESULTS}

Table I below represents information about the respondent's ages, educational level, marital status and occupation to determine reasons for access lack of access. The women were 15-49 years, with a mean age of 35.2 years. Majority of the women $(85.7 \%)$ were married. Almost all the respondents (94\%) had formal education. Two hundred and nine respondents' $(26.7 \%)$ were petty traders, $43.9 \%$ fewer, $9.5 \%$ artisans, $5.8 \%$ civil servants and $6.0 \%$ were unemployed. Most of the respondents were aged between 15-39. This is very important because the women in these age brackets were still active in social and sexual life, hence still having children and should need the services at the health centres more. This made the research and the results very timely and strategic toward meeting the major problems under study for solutions.

Table 1: Socio-Demographic Information of Respondents

\begin{tabular}{|l|c|c|}
\hline Characteristics & Frequency & Percentage \\
\hline Age Group & & \\
$15-19$ & 5 & 0.8 \\
$20-24$ & 21 & 3.5 \\
$25-29$ & 107 & 17.8 \\
$30-34$ & 156 & 26.0 \\
$35-39$ & 149 & 24.8 \\
$40-44$ & 87 & 14.5 \\
$45-49$ & 75 & 12.5 \\
& & \\
Marital status & & 85.7 \\
Married & 514 & 6.7 \\
Single & 40 & 0.8 \\
Separated/Divorced & 5 & 6.8 \\
Widowed & 41 & \\
Educational Qualification & & 6.0 \\
No formal education & 36 & 40.7 \\
Primary school & 224 & \\
\hline
\end{tabular}




\begin{tabular}{|l|c|c|}
\hline Secondary school & 273 & 45.5 \\
Tertiary & 47 & 7.8 \\
& & \\
Occupation & 369 & 61.5 \\
Farming & 103 & 17.2 \\
Trading & 57 & 9.5 \\
Artisans & 35 & 5.8 \\
Civil Servants & 36 & 6.0 \\
Unemployed/Housewife & & \\
\hline
\end{tabular}

Source: Field Survey, 2011.

The figure below shows that more than half of the respondents indicated that attitude of health workers was the major factor considered in deciding where to go to or take their child for PHC services (51. $3 \%)$. Other factors include proximity to the health facility (37.9\%), the presence of medical doctor (28. $0 \%)$ and the lost of drugs etc.

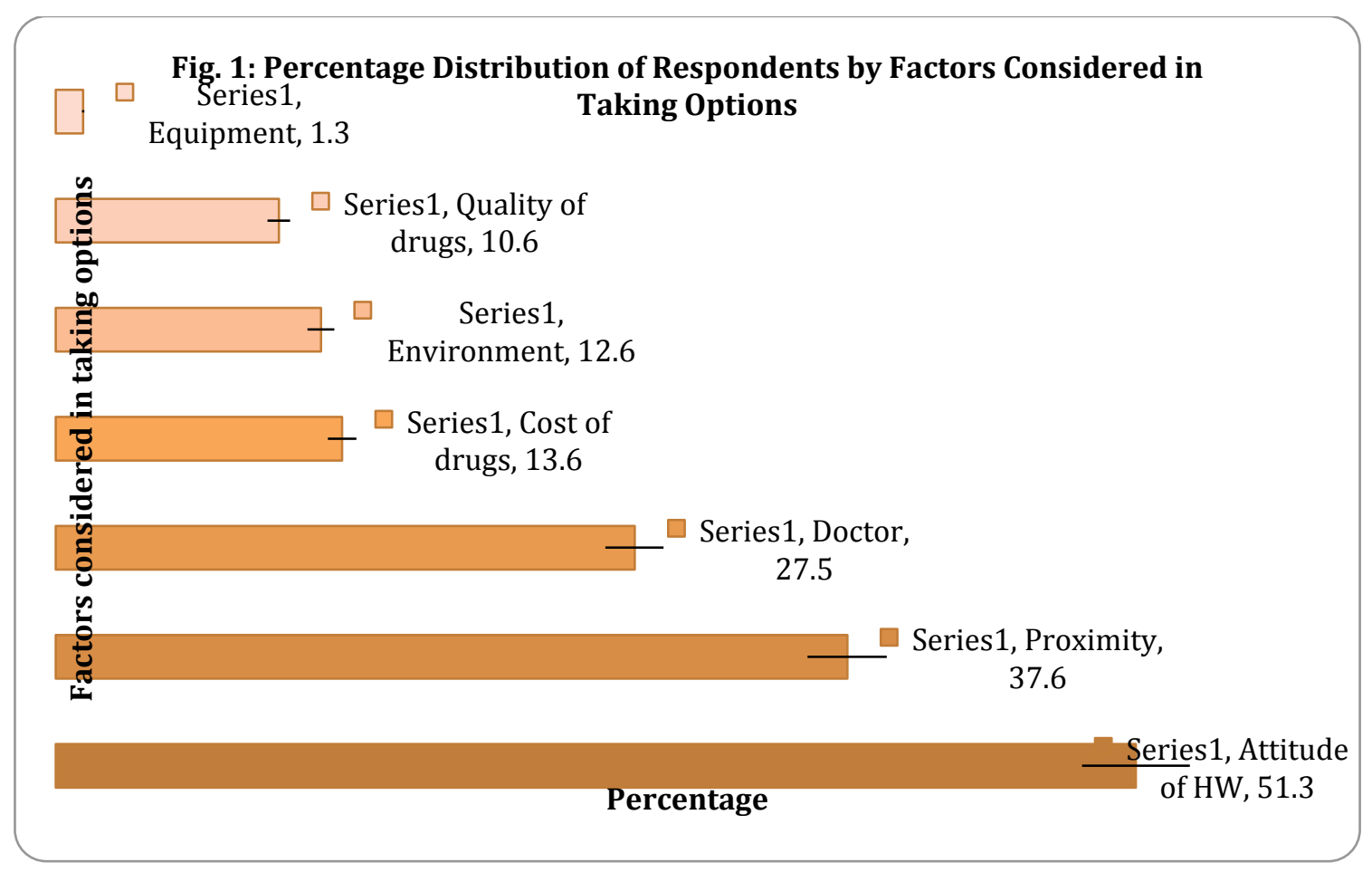

Information from the qualitative data gave more insight on the major factors considered in accessing PHC services with following statements.

Table 2 shows that the peoples' major problem in accessing health care was bad attitude of heath workers at the PHC centres (64.6\%). Another problem faced by the people was lack of facilities. This was mentioned by more than half (55.0\%) of the respondents. Furthermore, $44.3 \%$ of the respondents saw the management of the facility as a major constraint to access services in the PHC centres. Logistics and cost of services were the least identified problems experienced and mentioned by $3.5 \%$ and $7.1 \%$ of the respondents respectively.

The results of table 2 were clearly collaborated with the information revealed and gathered during the various FGDs held among groups in the area of study as will be seen in the sessions below under qualitative analysis. 
Table 2: Distribution of Respondents on Major Problems in Accessing Health Care services.

\begin{tabular}{|l|r|r|c|}
\hline Problems in accessing health care & Mentioned & Not Mentioned & \multicolumn{1}{l|}{ Total } \\
\hline Logistics & $21(3.5)$ & $579(96.5)$ & $600(100)$ \\
Costs & $42(7.1)$ & $558(92.9)$ & $600(100)$ \\
Management problems & $266(44.3)$ & $334(55.7)$ & $600(100)$ \\
Lack of facilities & $330(55.0)$ & $270(45.0)$ & $600(100)$ \\
Absence of medical doctors & $388(64.6)$ & $212(35.4)$ & $600(100)$ \\
\hline
\end{tabular}

Source: Authors Field Survey 2011

\section{QUALITATIVE ANALYSIS}

The qualitative data also complements the quantitative data with the following responses from the various FGD sections conducted in the LGA.

You see if I remember the way the health workers relate to us, I will not want to go to the health center, instead I will just go and buy drugs and have my rest of mind. (Participant: FGD; Female Community member Nanka.)

Coming to your question, these two health centre in our community are almost the same because if you go to the one at Oshukwu, there is a big failure there. The nurses there do not know how to receive customers. (Participant: FGD; Female Community member Awgbu.)

We want the Government to take what is happened at the health centre seriously. We only take our children to that place because we don't have another choice. (Participant: FGD; Male Community member Awgbu.)

In most cases, what prevents us from going there is that sometimes when you take a sick person to that place, you will not see the nurses there. Sometimes when you take the pregnancy woman in labour to that place at night you will not find the nurses there and such things discourages that prevents people from going to that health centre, instead, they would prefer to private hospital where the doctor will be available to treat them. [Participant: FGD; Female Community Member Ndiowu]

The nurse we have here are our major problem. They should change and everything will be fine. [Participant: FGD; Female Community Member Nanka]

In the past 4 years, say around 2009, there was a visiting doctor from the local government to the health centre but for about two years now, we have not seen any doctor there. [Participant: FGD; Male Community Member Omogho ]

The major problem we have in accessing the PHC here is that we don't have good nurses here. Apart from that, we don't have doctors at the health centres in and community. [Participant: FGD; Female

These qualitative responses were taken from different FGD sessions and each submitted similar experiences and all pointing to the activities of health workers in these centers, which according to them negatives their norms of reception and tolerance. 


\section{DISCUSSION}

Access to Primary Health Care services has constituted a major source of concern for governments, health administrators, NGOs and researchers globally. This is due to its linkage with preventable deaths especially maternal and child mortality which is generally high in Africa and Nigeria in particular. These concerns no doubt, have raised questions, informed inquiries and investigations into factors that hinder access to PHC services and how mothers react, manage and cope in the face of these challenges. There is the dear need for improved attitude and behavior on the part of the health workers to really influence positively the rural women towards accessing medical services in Primary Health Care. Some problems identified are discussed below to drive home our points as well as strengthen the social and health conditions of those in Orumba North whether as health care givers or as beneficiaries of the health care services. Generally, the study showed lack of discipline in terms of time to report for work by health workers.

The major problem was the attitude of health workers which is made manifest in absence of medical personnel's especially medical doctors, lateness to work, very long and unpredicted waiting time by patients to be attended to. The second was lack of health facilities. Brown et.al (1993) noted that these factors were very crucial as they determine the extent to which services are conveniently organized for prospective client and this encompasses such issues as clinic hours and appointment system, waiting time and mode of service delivery, attitude of health workers and buying of drugs outside the facility. The qualitative data confirmed these problems as some of the participants complained bitterly about these issues.

It is clear that though the various health management authorities from the interviews held tried to build and improve the social and psychological capacity of health workers towards relationships, majority as seen in this study are yet to comply with medical ethics geared towards clients first. This negates the peoples cultural pattern, norms and values for care and emotional sharing, hence fall prey to wrong medical alternative sources or self medications due to lack of confidence and fear of embarrassment by health personals.

Generally these findings agree with the empirical findings of Ensor and Copper (2004) on the role of demand-side barriers in impeding access to the use of health services. Further, the findings also agree with Frost \& Reich (2008) as they identified bottlenecks to access as a major problem in the use of health care services in developing countries.

The findings also agree with the structural basis for action theory which formed the theoretical framework for this study. It specifically states that the condition of the health facilities and workers attitude or behavior will influence the people's decision to visit or not to visit the centres.

Although a number of socioeconomic factors negatively affected access to PHC services, it is interesting to note that the PHCs in the LGA were the first port of calls despite their inadequacies. The research therefore recommends as have been earlier argued that there should be conscious provisions by Government more PHC centres adequate facilities and services. More capacity building workshops be designed for health workers in social and psychological understanding to improve care and relationship with clients. More advocacy visits and reconscientization moves to be established in line with other professionals like psychologists, social workers and anthropologists in rural areas to improve the knowledge base of the community members towards appreciating the and services of the health workers. 


\section{References}

Barbieri, M. (2004). Infact and child mortality in less developed world. International Encyclopedia of Social and Behavioural Science, Page 7404-7410.

Brown, I. Franco, L. Rafah, M. \& Hatzel, T. (1993). Quality Assurance of Health Care in Developing Countries. Quality Assurance Project Bethesda.

Ensor, T. \& Cooper, S. (2004). Overcoming barriers to health services access and influencing the demand side through purchasing. Washington, DC: The international bank for reconstruction and development.

Frost, L. \& Reich, M. (2008). Access: how do good Heath technologies get to poor people in poor countries? Cambridge: Massachusetts, Harvard centre for population and Development studies.

National Population Commission (2006). National and state population and housing tables: Priority table $1 \& 43$. Abuja. NPC

NPC \& ICF Macro (2009). Final report of Nigerian Demographic and health survey. Abuja: NPC

Ojua, T.A, Ishor,D.I \& Ndom,R,J.(2013). African cultural practices and health implications for Nigeria rural development. International review of management and business research.vol. 2, issue 1.

Okonofua, F. (2010). Reducing maternal mortality in Nigeria: An approach through policy research and capacity building. African Journal of Reproductive Health, 14(3), 9-13

Onokerhoray, G. (2000). Health and family planning services in Nigeria. Benin City: Social Science Series for Africa.

Onyeneho, N. (2005). Culturally defined gender equity response and delay- outcome index in the management of childhood fever among Mbaise people of south Eastern Nigeria. ( Doctoral dissertation, University of Nigeria, Nsukka 2005).

UNICEF.(2008). Goal: Reduce child mortality retrieved 28th March, 2011. From http://www.UNICEForg/mdg/childmortality.Html.

WHO (2006). Core health indictors: Comparison on core health indicator within WHO region. Geneva: WHO 